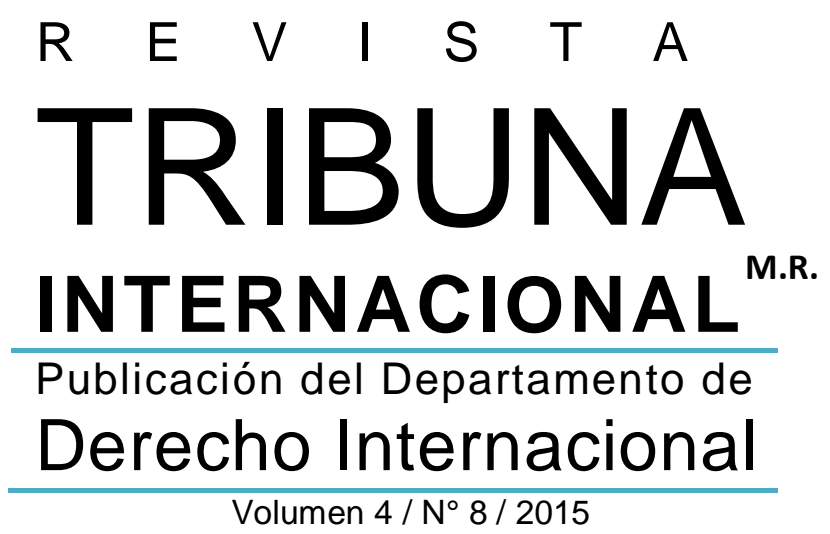

FACULTAD DE DERECHO 


\section{Rector de la Universidad de Chile}

Ennio Vivaldi Véjar

Av. Alameda Libertador Bernardo O'Higgins

1058, Santiago

\section{Representante legal}

Davor Harasic Yaksic

Decano de la Facultad de Derecho

Universidad de Chile

\section{Director Departamento Derecho}

Internacional

Edmundo Vargas Carreño

\section{Director (S) Revista Tribuna Internacional}

Mario Arnello Romo

\section{Editor General Revista Tribuna Internacional}

Luis Valentín Ferrada Walker

\section{Comité Editorial}

Íñigo Álvarez Gálvez (Universidad de Chile, Chile)

Gonzalo Aguilar (Universidad de Talca, Cbile)

José Carlos Fernández Rosas (Universidad

Complutense de Madrid, España)

Claudio Grossman (American University, EE.UU.)

Mattias Kumm (New York University, EE.UU.)

Hugo Llanos (Universidad Central, Chile)

Cecilia Medina (Universidad Diego Portales, Chile)

Elina Mereminskaya (Universidad de Chile, Chile)

Mónica Pinto (Universidad de Buenos Aires, Argentina)

\section{Fundador de la Revista Tribuna Internacional}

Mario Ramírez Necochea $†$

\section{Revista Tribuna Internacional M.R.}

Publicación del Departamento de Derecho Internacional de la Facultad de Derecho de la Universidad de Chile. Su objetivo es fomentar la reflexión, el debate, el análisis y la comunicación sobre el derecho internacional en forma pluralista y con rigor científico. Se publica cada semestre en los meses de junio y diciembre mediante convocatoria abierta a la publicación de artículos y monografías inéditos, comentarios de jurisprudencia, recensiones y comentarios de libros, en los campos de derecho internacional público y privado, derecho internacional de los derechos humanos y relaciones internacionales, tanto en castellano como inglés.

La Revista Tribuna Internacional fue creada por Decreto Exento No 8.466 de la Rectoría de la Universidad de Chile, de 22 de marzo del 2011.

Volumen 4/ No 8 / 2015

www.tribunainternacional.uchile.cl ISSN 0719-482X (versión en línea)

Departamento de Derecho Internacional Facultad de Derecho Universidad de Chile Av. Santa María 076, $4^{\circ}$ piso

Providencia, Santiago de Chile

\section{Diseño y producción:}

Facultad de Derecho

Universidad de Chile

Se autoriza la reproducción total o parcial del contenido de la publicación, siempre que se reconozca y cite el/ la/ los/ las autor/a/es/as y la publicación, no se realicen modificaciones a la obra y no se la utilice para fines comerciales. 


\title{
Excepciones Preliminares (Caso Bolivia c. Chile) ${ }^{1}$
}

\author{
Preliminary Objections (Case Bolivia v. Chile)
}

\section{Jaime Lagos Erazo}

jlagose@vtr.net

Abogado. Licenciado en Ciencias Jurídicas y Sociales de la Universidad de Chile. Profesor invitado de la Facultad de Derecho de Universidad de Chile

Resumen: Con posterioridad a la presentación, el 24 de abril de 2013, de una demanda por Bolivia contra Chile ante la Corte Internacional de Justicia de La Haya con respecto a una controversia "relativa a la obligación de Chile de negociar efectivamente con Bolivia, de buena fe, con el fin de llegar a un acuerdo que otorgue a Bolivia un acceso totalmente soberano al Océano Pacífico", se produjo en Chile un fuerte debate acerca de la conveniencia y oportunidad de presentar una excepción preliminar para objetar la competencia y jurisdicción de dicho tribunal para conocer ese caso. En vista de ello, en el presente trabajo se analizan las característica y modalidades que reviste dicha práctica en los procedimientos y la jurisprudencia de ese tribunal deteniéndose al final a examinar los fundamentos que condujeron al gobierno chileno a presentar una objeción preliminar en el caso en disputa.

Palabras clave: Controversia sobre obligación de negociar - objeción preliminar - Caso Bolivia c. Chile.

\begin{abstract}
In the aftermath of the of the submission to the International Court of Justice of The Hague, on 24 April 2013, of an application of Bolivia instituting proceedings against Chile concerning a dispute in relation to "Chile's obligation to negotiate in good faith and effectively with Bolivia in order to reach an agreement granting Bolivia a fully sovereign access to the Pacific Ocean" a debate arose in Chile over the convenience and timing of raising a preliminary objection to the jurisdiction of the Court in that case. Due to the above, in the present essay it is explained the modalities and the practice of the Court concerning the submission of preliminary objections and its application to the case Bolivia v. Chile.
\end{abstract}

Keywords: Dispute concerning the obligation to negotiate - preliminary objections - Case Bolivia v. Chile.

1 Síntesis de la exposición del Profesor Jaime Lagos en acto académico de la Facultad de Derecho de la Universidad de Chile (25 de septiembre de 2015). 


\section{Chile interpone excepciones preliminares}

A raíz de la presentación, el 24 de abril de 2013, de la demanda boliviana ante la Corte Internacional de Justicia (CIJ), de inmediato surgió en nuestro país una fuerte y mayoritaria corriente de opinión que rechazó enérgicamente la competencia o jurisdicción de dicho tribunal para conocer de una demanda calificada de artificiosa y sin ningún fundamento legal. De manera unánime se opinó que esa demanda, a todas luces, no era solamente contraria al derecho, sino más bien un libelo político que traduce meras expectativas (derechos expectaticios, como fueron inicialmente definidos), las que fundamentalmente buscan la revisión del Tratado de Paz y Amistad de 1904, que estableció definitivamente y a perpetuidad los límites entre Chile y Bolivia.

Como se recordará, de inmediato se originó en nuestro país una disputa interna que estuvo fundamentalmente centrada en el mecanismo y en la oportunidad más conveniente que debía emplear nuestro gobierno para objetar la competencia o jurisdicción y la admisibilidad de dicha demanda por ese tribunal, conforme a las normas que regulan sus procedimientos contenciosos.

Las opciones que se barajaron fueron básicamente las que la doctrina califica como "clásicas" (principalmente las excepciones preliminares que se encuentran contempladas en el artículo 79 del Reglamento de la Corte). Hubo también un debate más bien periodístico en torno a una fórmula que se empleó en el pasado para reclamar por la incompetencia de la Corte pero sin participar en el litigio, utilizando el mecanismo de la no comparecencia (o rebeldía), pero ésta última opción no fue una alternativa contemplada a nivel gubernamental, por sus evidentes desventajas.

Para recoger opiniones sobre la conveniencia de objetar la jurisdicción y la competencia de dicho tribunal para conocer esta demanda (o su admisibilidad) y respecto de cuál sería la ocasión más conveniente para hacerlo, el gobierno de la Presidenta Bachelet emprendió desde un comienzo amplias y transversales consultas con distintos sectores nacionales y con sus abogados extranjeros.

Por un lado, amplios sectores nacionales reclamaron que el gobierno pidiera a la Corte que se declarara incompetente de inmediato, levantando dichas excepciones preliminares, por cuanto al contestar la demanda "se le otorgaba legitimidad" (lo que es discutible legalmente), siendo necesario desde un comienzo dar una señal de rechazo jurídico y político a la insólita demanda boliviana, y evitar que el tema de la incompetencia se diluyera con otros argumentos que fueran invocados durante la tramitación del pleito. Asimismo, se argumentó que si bien las posibilidades de éxito eran escasas (30 a 40\%) nuestro país no podía renunciar anticipadamente a un recurso procesal que estaba a su disposición. 
Finalmente y después de haberse ponderado los riesgos y ventajas que presentaban ambas alternativas, con fecha de 7 de julio de 2014, se anunció que Chile “objetaría la competencia de la Corte Internacional de la Haya, presentando para ello Objeciones Preliminares dentro del plazo previsto para estos efectos (15 de julio [de 2014])".

Se añadió entonces, en palabras del Canciller Heraldo Muñoz, que otras de las razones de fondo que se habían tomado en consideración para tal efecto y que constituyen el eje central de la posición chilena en la materia, fueron que "Chile y Bolivia establecieron sus límites definitivos en el Tratado de Paz y Amistad de 1904, el cual ha sido respetado e implementado por ambos Estados por más de un siglo, llegando a la convicción que estaban dadas las condiciones para oponer la excepción preliminar y para que la Corte pueda resolver en esta etapa temprana, que no tiene jurisdicción en este caso". Agregó que "era necesario enviar un mensaje claro e inequívoco de incompetencia desde un inicio", añadiendo que la Corte "ha acogido y también rechazado excepciones preliminares, pero que hay que tener confianza en que vamos a ganar. Creo que un rechazo a las excepciones es remoto, aunque la Corte podría hipotéticamente remitir nuestras objeciones al fondo del caso". Posteriormente, en una entrevista en un programa de televisión (Tolerancia Cero), de 21 de julio del 2014, reconoció que hay "elementos a favor y en contra de presentar ahora excepciones preliminares. A la postre, la Presidenta Bachelet resolvió aprovechar todos los pasos procesales disponibles" y que "no era conveniente excluir ahora esa posibilidad que se puede reiterar a la Corte durante el fondo, siendo necesario dar desde ahora una señal clara a los jueces y a la comunidad internacional". Consultado acerca de si la Corte podía reconocerse competente, el jefe de la diplomacia chilena acotó que esa posibilidad era muy remota ("un $2 \%$ de probabilidades"). Con todo, no desconoció que la "Corte puede también decir como otra alternativa que 'sus argumentos son muy interesantes pero tocan el fondo, en consecuencia lo remito al fondo', situación que tiene mayores posibilidades".

En efecto, no se podía desconocer que en todo caso siempre se cierne la posibilidad que la Corte, ante las evidencias aportadas por las Partes, se vea impedida de adoptar una decisión preliminar. Ello lo dejó entrever el Presidente de la Corte, Peter Tomka, al responder a una consulta en un foro jurídico que se celebró en Washington en ese tiempo, cuando expresó que la "frontera entre los dos países no la vamos a resolver. [...] La Corte tendrá que decidir si Chile asumió en el pasado una obligación de conceder una salida soberana al mar y si ha cumplido con esa obligación" admitiendo que "los jueces tendrán que evaluar la admisibilidad de los argumentos bolivianos. Definir si el caso tiene fondo" y "sólo entonces definir si existen obligaciones por parte de Chile y su cumplimiento". De paso, recordó que así la Corte lo hizo en 1997, en el caso de Hungría contra Eslovaquia por la construcción de las represas hidroeléctricas Gabcikovo-Nagymaros, donde obligó a las partes a negociar de buena fe el cumplimiento del tratado que firmaron 20 años antes, cuando aún existía Checoslovaquia.

Debido a este autorizado y premonitorio testimonio y otras consideraciones tales como que la Corte en sus últimos fallos se había manifestado poco dispuesta a ceder su competencia a las 
Partes y que había un mayoría recientes de ellos que habían rechazado las excepciones preliminares, me llevaron en lo personal al convencimiento que no era favorable a nuestros intereses perder en los comienzos del juicio un incidente procesal. Sin embargo, finalmente me pareció más conveniente a los intereses del país no mostrarme como una voz disidente y mantener una opinión nacional unida, acogiendo como un mal menor los riesgos ya evocados por nuestras autoridades.

\section{Bolivia protesta por acción chilena}

En este relato nos parece oportuno recordar que tan pronto se anunció que Chile objetaría la competencia de la Corte, en Bolivia, su Presidente Evo Morales señaló que esa impugnación ubicaría a nuestro país "al margen del marco que rige el derecho internacional", todo lo cual, por cierto, no tiene ningún asidero, por cuanto el hecho de impugnar la competencia o jurisdicción de la Corte es un derecho expresamente concedido a los demandados en el ámbito de las causas que conoce la CIJ, reconocido en su Estatuto y Reglamento, como veremos más adelante.

En efecto, la impugnación de la competencia de la Corte o de la admisibilidad de una demanda, se presenta con mucha frecuencia debido a que la jurisdicción de este tribunal es de carácter esencialmente voluntario, toda vez que opera con el consentimiento de los Estados involucrados. Cuando uno de ellos adopta el paso de presentar una demanda en contra del otro, es debido a que ambas Partes han otorgado previamente su consentimiento respecto al ejercicio de la jurisdicción por la Corte. Tratándose de una jurisdicción enteramente consensual, no hay nada reprochable en que un Estado que se encuentre en esa situación busque evadir un litigio que él mismo no ha buscado.

En el caso de Chile y Bolivia, por el Pacto de Bogotá de 1948 sobre la Solución Pacífica de las Controversias las Partes contratantes reconocieron respecto de cualquier otro Estado americano como obligatoria ipso facto, sin necesidad de ningún convenio especial, la jurisdicción de la CIJ en todas las controversias jurídicas que surjan entre ellas.

De tal suerte, la impugnación de la jurisdicción de la CIJ constituye un curso de acción perfectamente legítimo para cualquier Estado en contra del cual se presente una demanda ante ella y que esté convencido de que no ha otorgado su consentimiento con relación a esa controversia específica, por no ajustarse ésta a los parámetros fijados en el artículo VI del Pacto de Bogotá. 


\section{Consideraciones generales sobre la presentación de las excepciones preliminares}

En el Estatuto de la CIJ, cuando un Estado parte es objeto de una demanda ante ese tribunal, tiene normalmente tres caminos a su disposición para impugnar su competencia o jurisdicción (ambas expresiones tienen igual significado):

(i) Acudir ante la Corte y presentar una defensa sobre el fondo de la materia de que trate la demanda, incluyendo los aspectos jurisdiccionales, como acaeció en la controversia marítima del Perú contra Chile;

(ii) No comparecer ante la Corte; $y$

(iii) Impugnar la competencia de la Corte o la admisibilidad de la demanda anticipadamente, es decir, adoptar un camino intermedio mediante el cual el Estado acude a la Corte no para defender el fondo del litigio, sino que para demostrarle al tribunal, con argumentos de carácter jurídico, que éste no debe entrar a conocer del caso por carecer de competencia o que la demanda no es admisible, interponiendo excepciones u objeciones preliminares.

Según la definición clásica de Basdevant, la excepción preliminar es "un medio invocado durante la primera fase de la instancia y tendiente a obtener que el tribunal decida una cuestión previa antes de abordar el examen del fondo del asunto, cuyo objetivo más común es obtener que no se pase al examen del fondo"2.

Otra definición muy repetida señala que una excepción preliminar es "cualquier excepción que, de ser admitida, produce el efecto de interrumpir el procedimiento en el caso y que por tanto hace aconsejable que la Corte la considere antes de entrar al fondo del asunto".

En sentido puramente procesal, la formulación de excepciones preliminares tiene dos importantes secuelas. Por un lado, al momento de presentar las excepciones, el procedimiento sobre el fondo se suspende y se abre un procedimiento incidental, en limine litis, consagrado a las cuestiones previas de jurisdicción y/o admisibilidad que hayan sido planteadas por medio de dichas objeciones (Reglamento de la CIJ, artículo 79.5).

En segundo lugar, como el procedimiento incidental sobre las excepciones es iniciado por el demandado, se invierten los roles procesales y este Estado es el que debe presentar sus alegatos en primer lugar, tanto el alegato escrito (las propias excepciones preliminares) como al intervenir en las audiencias públicas que debe convocar la Corte. Al demandante le corresponde entonces en esta fase, un papel esencialmente reactivo, el cual desempeña

2 Basdevant, Jules. Dictionnaire de la terminologie du Droit Internationale. París, Sirey, 1960. 
mediante el depósito de una "Exposición Escrita" en respuesta al escrito de excepciones, seguidas de su intervención en la audiencia para controvertir los alegatos que presente el demandado. Si las excepciones son rechazadas, en forma total o parcial, los dos Estados regresan a sus roles naturales de demandante y demandado y en esa condición siguen participando en los procedimientos escritos y orales que todavía sean necesarios.

\section{Mecanismos para impugnar la competencia}

Para impugnar la competencia de la Corte o la admisibilidad del caso existen tres mecanismos procesales alternativos que presentan importantes diferencias en el fondo y en la forma.

a) Procedimiento tradicional: formulación de excepciones preliminares.

El escrito de excepciones debe presentarse "tan pronto como sea posible, y no más tarde de tres meses después del depósito de la memoria”.

b) Procedimiento alternativo: discusión separada de las cuestiones de jurisdicción y admisibilidad

Este segundo mecanismo consiste en que el Estado demandado puede intentar de persuadir a la Corte de que se abstenga de conocer del fondo del asunto y le manifieste al tribunal en una fecha muy temprana - por ejemplo, durante la primera reunión de los agentes de las Partes con el Presidente de la Corte, cuyo objetivo es recoger las opiniones de los dos gobiernos sobre los plazos a fijarse para la presentación de las piezas iniciales del procedimiento escrito- que en su opinión la Corte carece de jurisdicción o la demanda es inadmisible.

c) La presentación de excepciones junto con el fondo

Una tercera alternativa procesal para impugnar la competencia de la Corte o la admisibilidad de la demanda es que las partes en el caso pueden acordar entre ellas que cualquier excepción en ese sentido sea oída y resuelta por la Corte junto con el fondo del asunto. 


\section{Modalidades que pueden revestir las excepciones}

Dentro de este marco, en los litigios contenciosos ante la Corte pueden existir tres tipos de excepciones preliminares, a saber:

i) Excepciones a la competencia de la Corte, que se refieren al título o base de jurisdicción invocado por la otra Parte argumentado por ejemplo que el instrumento en el cual se fundamenta dicho título o base de competencia es nulo o ya no está en vigor; que la controversia a la cual se refiere la demanda es anterior a la fecha límite mencionada en dicho título o cae dentro de las reservas incluidas por los Estados partes.

ii) Excepciones sobre la admisibilidad de la solicitud. El Estado demandado puede sostener que en la introducción del litigio no se han observado por ejemplo ciertas disposiciones del Estatuto o del Reglamento; que la controversia no existe o carece de objeto o no es de naturaleza jurídica en el sentido del Estatuto; que el demandante carece de interés jurídico en el asunto o de personalidad para actuar (locus standi); que no se han agotado otras posibilidades de solución de la controversia que constituyen requisitos previos al recurso judicial, etc.

iii) Una categoría residual que comprende "cualquier otra excepción sobre la cual el demandado pide que la Corte se pronuncie antes de continuar el procedimiento sobre el fondo".

El jurista, Pierre Marie Dupuy formula una descripción similar aunque en otros términos más simples, indicando que estas excepciones pueden apoyarse sobre la base de distintos tipos de argumentos. La incompetencia rationae personae se presenta cuando un Estado considera que el otro Estado no tiene la calidad (también se habla de la capacidad) necesaria para actuar ante la Corte. La incompetencia rationae materiae concierne la inexistencia de un diferendo jurídico actual y de carácter internacional (requisito indispensable según el artículo 36 de su Estatuto para incoar una demanda) $)^{3}$ y finalmente rationae temporis cuando, entre otras razones, han expirado los plazos de un compromiso unilateral o convencional ${ }^{4}$.

Con relación al aspecto relativo a la existencia de un diferendo, la definición aceptada tradicionalmente desde el fallo de la objeción preliminar de jurisdicción por la Corte

3 El artículo 31 del Pacto de Bogotá es del siguiente tenor: "De conformidad con el inciso 2 del artículo 36 del Estatuto de la Corte Internacional de Justicia, las Altas Partes Contratantes declaran que reconocen respecto a cualquier otro Estado americano como obligatoria ipso facto, sin necesidad de ningún convenio especial mientras esté vigente el presente tratado, la jurisdicción de la expresada Corte en todas las controversias de orden jurídico que surjan entre ellas y que versen sobre:

a) La interpretación de un tratado.

b) Cualquier cuestión de derecho internacional.

c) La existencia de todo hecho, que, si fuere establecido constituiría la violación de una obligación internacional.

d) La naturaleza o extensión de la reparación que ha de hacerse por el quebrantamiento de una obligación internacional".

4 Dupuy, Pierre Marie. Droit International Public. París, Dalloz, 1992. 
Permanente de Justicia Internacional (CPJI) en el caso Mavrommantis (1924), es que "una controversia es un desacuerdo sobre un punto de derecho o de hecho, una contradicción, una oposición de tesis jurídicas e intereses" ${ }^{\prime 5}$. En otros fallos, también se ha dictaminado que dicha controversia debe ser permanente y reiterada en el tiempo.

Como puede apreciarse, el umbral para determinar lo que es o no una "controversia jurídica" es bastante amplio. Al respecto, el jurista Malcolm Shaw, después de analizar los casos de Timor Oriental de 1995 y de Genocidio (Bosnia y Herzegovina c. Yugoslavia, 1996), que "fijaron umbrales muy estrechos para determinar lo que constituye una disputa legal", concluye que "en otras palabras, para que una materia constituya una disputa legal, es suficiente que el demandado ante la Corte niegue las alegaciones inclusive si la jurisdicción de la Corte está siendo cuestionada"\%.

Una vez oídas las partes, la Corte fija una fecha para la lectura de su decisión, la cual puede contemplar una de tres soluciones, como ya lo vimos con anterioridad:

i) La Corte acepta al menos una de las excepciones formuladas por una de las Partes, caso en el cual el litigio llega a su término y debe ser removido de la Lista General de la Corte (si bien hay otras variantes, aceptación parcial, como se indica más adelante).

ii) La Corte rechaza una por una todas las excepciones formuladas, afirmando su jurisdicción para conocer del caso y, de ser necesario, determinando la admisibilidad de la demanda. En esta alternativa, el procedimiento sobre el fondo se reanuda en el punto en que fue interrumpido y la Corte fija una fecha para la presentación del siguiente escrito, que normalmente es la primera alegación sobre el fondo del Estado que formuló las objeciones.

iii) La Corte declara que, en las circunstancias del caso, la objeción u objeciones de que se trata no poseen un carácter exclusivamente preliminar. En este caso el resultado procesal es idéntico al del caso anterior, y la Corte debe proceder a fijar el siguiente plazo dentro del procedimiento escrito sobre el fondo.

Como se ha expresado, a mayor abundamiento y precisión, la Corte, en caso que esas objeciones se presenten, tiene tres opciones, según la autorizada opinión de Rosenne: a) aceptar la objeción o las excepciones si son más de una ${ }^{7}$, fallo que puede conducir a dar por terminado el procedimiento o proseguir sobre otras bases de jurisdicción más limitadas; b) rechazarla(s), reanudándose la discusión sobre los méritos, y c) declarar que ella o ellas no poseen, en el marco de las circunstancias del caso, un carácter exclusivamente preliminar.

5 CPJI (1924) A2, p. 11. Caso de las concesiones palestinas Mavrommatis. Objeción preliminar de jurisdicción (Grecia c. Reino Unido).

6 SHAW, Malcolm. International Law. 4a edición. Cambridge, Cambridge University Press, 1997.

7 En la controversia terrestre y marítima entre Nicaragua contra Colombia, la Corte aceptó una excepción preliminar parcialmente e inclusive la fragmentó. 


\section{Práctica de las excepciones preliminares}

Durante el período de la anterior CPJI, los casos en que se formularon tales excepciones fueron 13. Con la actual CIJ la presentación de objeciones preliminares ha sido cada vez más frecuente y constituye una actividad principal de dicho tribunal.

Como anotó la ex Presidenta del Tribunal, Rosalyn Higgins, de los 97 fallos que había emitido la Corte desde 1946 hasta 2008, en 44 de ellos había sido necesario celebrar audiencias separadas para discutir aspectos jurisdiccionales, aunque la mayoría de ellos se referían a controversias sobre la "cláusula opcional"; esto es, de aquellos Estados que aceptaron suscribir esa cláusula reconociendo la jurisdicción de la Corte en todos los casos ${ }^{8}$.

El jurista Antonio Remiro Brotóns, por su parte, señala que los demandados antes que los demandantes (la excepción la hizo Italia en el asunto del Oro Monetario, 1954) presentan "a menudo" excepciones preliminares, y que así se hizo en 15 de los 25 casos planteados unilateralmente ante la CIJ entre 1990-2010. Sin embargo, en sólo seis de ellos los demandados tuvieron éxito: Timor Oriental (Portugal c. Australia, 1995); Pesquerías Transzonales (España c. Canadá, 1998); Incidente Aéreo de 10 de agosto de 1999 (Pakistán c. India, 2000); Licitud de empleo de la fuerza (Serbia y Montenegro c. Reino Unido, Portugal, Países Bajos, Italia, Alemania, Francia, Canadá y Bélgica, respectivamente, 2004); Ciertos bienes (Liechtenstein c. Alemania, 2005); Acciones armadas en el Congo (Congo c. Ruanda, 2006); y parcialmente en Controversia Territorial y Marítima (Nicaragua c. Colombia, 2007) ${ }^{9}$.

Por su parte, la conocida jurista boliviana Karen Longaric, en un artículo de prensa publicado el 2011, sostuvo que "en la mayoría de los procesos judiciales instaurados ante la CIJ, la parte demandada ha hecho uso del recurso procesal de las excepciones, objetando la competencia de ese tribunal. En un porcentaje ostensiblemente mayoritario, la CIJ ha rechazado dichas excepciones, declarándose competente para dirimir la controversia entre Estados”. Agregó que "muy pocas excepciones de falta de competencia han sido aceptadas por la CIJ. La Corte decidió que no tenía competencia para conocer las pretensiones formuladas en la demanda presentada por Serbia y Montenegro contra Bélgica el año 1999. En la causa relativa a Determinados bienes (Liechtenstein contra Alemania), el 10 de febrero de 2005, la Corte decidió que no tenía competencia para conocer de la demanda presentada por Liechtenstein"

En nuestro país, dos influyentes periódicos intentaron también avanzar cifras para medir el éxito que tuvo en el pasado la introducción de tales excepciones preliminares, en el comportamiento de la Corte. Conforme a un análisis aparecido en el diario El Mercurio, "en los

Higgins, Rosalyn. Discurso ante la Sexta Comisión de la Asamblea General de Naciones Unidas. 31 de octubre de 2008. Remiro Brotons, Antonio. Derecho Internacional Público. Curso General. Valencia, Tirant Lo Blanch, 2010, p. 650.

10 LONGaric, Karen, en diario La Razón, La Paz (Bolivia), 27 de julio de 2011. 
133 casos que la Corte ha recibido, en 54 se ha realizado la citada gestión. Esto equivale a un $40 \%$ de las controversias". De ellas, acota que "cuando la CIJ ha reconocido no tener jurisdicción dicho porcentaje sube a 59\%, pues ha sucedido 32 veces"11.

El diario La Tercera, por su parte, llegaba a la conclusión que desde que comenzó a funcionar en 1946, la CIJ había recibido "29 excepciones preliminares, dentro de los más de 160 casos que se han ventilado en su historia" y que "del total, en 16 oportunidades la CIJ las ha rechazado", lo que llevaba dicha crónica a concluir que "La Haya rechazó la mayoría de las excepciones preliminares revisadas". Ese rechazo es mayor, acota, si se tiene en cuenta que ocho de ellas corresponden a un mismo caso (Legalidad del uso de la Fuerza) de SerbiaMontenegro contra ocho países de la OTAN. En ese caso, la aceptación de las excepciones preliminares, según el mismo periódico "bajaría tan solo a seis"12.

Estas discrepancias en los números son muy comprensibles toda vez que un análisis de cada uno de los casos en que desde 1946 se han invocado tales excepciones ante la CIJ, como también de sus resultados, es una tarea muy ardua y compleja ya que para obtener una mayor precisión estadística sería indispensable examinar cada sentencia que se haya pronunciado sobre las excepciones preliminares presentadas en cada caso (las que pueden ser varias en cada uno), y los otros fallos que se refieren a las llamadas cuestiones de "competencia y admisibilidad", conforme a una nueva práctica de la Corte.

\section{No comparecencia}

Como ya lo señalamos anteriormente, una de las Partes (normalmente el Estado demandado) puede también hacer uso del artículo 53 del Estatuto ${ }^{13}$ que prevé la situación de que una de ellas no comparezca o se abstenga de defender su caso ${ }^{14}$. Esta situación puede obedecer a diferentes causas (básicamente por cuanto rechaza la jurisdicción de la Corte).

En estos casos muy poco frecuentes, normalmente la Parte demandante solicitará al tribunal que le adjudique el caso, pero el tribunal entonces tiene una doble obligación, como se desprende de la lectura del artículo transcrito: de un lado debe asegurarse, antes de adoptar su decisión de que tiene competencia "conforme a las disposiciones de los artículos 36 y 37" y,

1 ElMercurio, 4 de mayo de 2011 (D5).

12 La Tercera, 9 julio de 2014.

13 Estatuto de la CIJ, art. 53.- 1. Cuando una de las partes no comparezca ante la Corte, o se abstenga de defender su caso, la otra parte podrá pedir a la Corte que decida a su favor.- 2. Antes de dictar su decisión, la Corte deberá asegurarse no sólo de que tiene competencia conforme a las disposiciones de los Artículos 36 y 37, sino también de que la demanda está bien fundada en cuanto a los hechos y al derecho.

14 La no comparecencia o juicio en rebeldía, como se describe esta situación en los textos en español, recibe otras denominaciones en inglés "non appearance" y en francés "procedure par défaut". 
por otra parte, debe cerciorarse de que la demanda está bien fundada en cuanto a los hechos y el derecho.

La primera de estas condiciones sin duda es un elemento favorable toda vez que representa la única oportunidad en que el Estatuto le asigna a la Corte la facultad de determinar motu propio si posee o no jurisdicción, en un caso que le ha sido sometido. Seguramente es por esta razón que cuando arreciaba en nuestro país la molestia por la demanda boliviana y se discutía la competencia de la Corte para conocerla, se trajo a colación este tema, argumentándose primero que era un "descubrimiento"; luego que no había literatura al respecto; en seguida, que estaba descrito en boletines informativos de las Naciones Unidas, etc. lo que no se condice lamentablemente con la realidad por cuanto si esta "excepción definitiva", como también la describen sus autores, podría poner, valga la redundancia, definitivamente término a la absurda pretensión boliviana, sería una solución ideal para evitar un juicio que Chile no ha buscado.

Empero, al sugerirla se olvidó comentar por sus proponentes que la Corte, una vez establecida su competencia, sigue adelante con el juicio en ausencia del "Estado rebelde o recalcitrante" (en inglés "the unwilling respondent") con alegatos escritos y orales de parte del demandante y el tribunal lo falla normalmente sin haber conocido las evidencias del Estado ausente (a veces éstos se la ingenian para transmitirles sus posturas por otras vías extra judiciales). En cada una de las sentencias que ha emitido al respecto, generalmente la Corte lamenta la ausencia de una de las partes y falla conforme a derecho, aunque reconoce que no ha podido conocer la versión completa de la posición del demandado. Esa sentencia es de cumplimiento obligatorio, como lo son todas las sentencias de la Corte, de conformidad con lo establecido en la Carta de las Naciones Unidas (artículo 94, inciso primero), con la posibilidad de sanciones de parte del Consejo de Seguridad. Hasta ahora sólo un país, los Estados Unidos, ha desafiado el cumplimiento de una sentencia de la Corte mediante el uso del poder de veto ${ }^{15}$.

Ello explica el hecho que cuando Colombia, en 1971, se vio enfrentada a una demanda de Nicaragua por el dominio territorial y marítimo en el Mar del Caribe, en dicho país se estudiaron todas las posibilidades para impugnar la competencia de la Corte para conocer ese caso y también se planteó la duda si debía comparecer ante el tribunal. Su respuesta ante ese dilema se explica por si sola leyendo el Libro Blanco de su Cancillería:

"Teniendo en cuenta que Colombia había aceptado la jurisdicción obligatoria de la CIJ cuando ratificó el Pacto de Bogotá en 1968 la no comparecencia implicaba para nuestro país un riesgo aún mayor. La principal consecuencia de carácter jurídico hubiese sido que la Corte habría continuado con el proceso en ausencia de Colombia, de conformidad con lo dispuesto en el artículo 53 de su Estatuto. Este artículo establece además que cuando una de las partes no comparece ante la Corte o se abstiene de defender su caso, la otra, en este caso Nicaragua, podía haber pedido que

15 Ver además, Lagos Erazo, Jaime. El Fallo de La Haya. Controversia marítima Perú contra Chile. Santiago, J.C. Sáez Editor, 2014, p. 225. 
se decidiera a su favor. Si la Corte, en esas circunstancias, fallaba a favor de Nicaragua, Colombia habría estado obligada por el Estatuto de la CIJ y la Carta de las Naciones Unidas a cumplir dicha sentencia, la cual además es inapelable. Por lo tanto, no comparecer habría privado a Colombia de la posibilidad de hacer valer sus argumentos en una materia vital para los intereses nacionales, por tratarse de un asunto relativo a la soberanía e integridad territorial" 16.

De más está decir que la mayoría de los principales expertos en esta disciplina, incluyendo una de las mayores figuras del Derecho Internacional, Sir Gerald Fitzmaurice, rechazan esta opción, aunque no en los términos tan duros como los que emplea el destacado jurista chileno Santiago Benadava, ${ }^{17}$ al referirse a "la corruptela de la no comparecencia que menoscaba el prestigio a la dignidad de la función judicial”"18.

Las publicaciones oficiales de la Corte y el propio Rosenne enjuician esta práctica con una mirada más indulgente, explicando más bien sus causas y como una tendencia pasajera. Dicen que ella se originó en los años 70 y 80 del siglo XX en momentos que había cierto escepticismo sobre la labor de la Corte, pero después de las modificaciones que se introdujeron a su procedimiento esa percepción varió y el último caso conocido de su aplicación se registró en 1984 en el controvertido caso de las actividades Militares y Paramilitares en y contra Nicaragua (fase de fondo y reparaciones), ocasión en que Estados Unidos empleó esta fórmula, además de haber formulado objeciones de competencia y admisibilidad, para evadir una sentencia negativa en diversos aspectos.

En los otros ocho casos, la no comparecencia se ha registrado en algunas o todas las fases del pleito: Canal de Corfú (Reino Unido c. Albania); Anglo Iranian Oil Company (Reino Unido c. Irán); Nottebobm (Lichenstein c. Guatemala); Jurisdicción sobre Pesquerías (Reino Unido c. Islandia) (Alemania c. Islandia); Ensayos Nucleares (Australia c. Francia)(Nueva Zelanda c. Francia); Juicio de Prisioneros Pakistanies de Guerra (Pakistán c. India); Plataforma Continental del Mar Egeo (Grecia c. Turquía); y Personal Diplomático y Consular de los Estados Unidos en Teherán (Estados Unidos c. Irán). En algunos de estos casos se produjo finalmente el desistimiento del Estado demandado.

16 República de Colombia. Ministerio de Relaciones Exteriores. Abecé. Demanda de Nicaragua contra Colombia ante la Corte Internacional de Justicia (CIJ) (folleto). Bogotá, Ministerio de Relaciones Exteriores de Colombia, c.2013, p. 6.

17 Profesor de Derecho Internacional Público, embajador en misión especial ante la Santa Sede para la Mediación Pontificia sobre el diferendo austral y árbitro en el caso de Laguna del Desierto. Es reconocidos como uno de los más destacados juristas chilenos.

18 Benadava, Santiago. Derecho Internacional Público. $7^{\text {a }}$ edición. Santiago, ConoSur LexisNexis Chile, 2001, pp. 351-353.. 


\section{Itinerario de la objeción chilena}

Como se ha indicado, el 15 de julio de 2014, Chile presentó su objeción preliminar y consecuentemente el Presidente de la CIJ suspendió el procedimiento sobre el fondo hasta tanto no se resolviera este incidente procesal. Seguidamente fijó un plazo para que Bolivia entregara un escrito con sus observaciones y peticiones relativas a la objeción preliminar chilena.

Cumplido ese requisito el caso quedó listo para los alegatos orales de las partes los cuales se verificaron entre el 4 y el 8 de mayo del 2015.

Inmediatamente antes de los alegatos, la Corte hizo públicos la objeción preliminar de Chile y las observaciones escritas de Bolivia.

El paso siguiente fue la dictación del fallo de 24 de septiembre de 2015, que se reproduce en esta Revista.

Los antecedentes descritos en los acápites anteriores configuran el escenario procesal que enmarcó el desarrollo de la objeción preliminar interpuesta por Chile.

Esta prosiguió luego, según dijimos, conforme al citado itinerario hasta que se dictara el fallo respectivo.

Sin perjuicio de lo que antecede, hemos creído útil proporcionar adicionalmente los antecedentes que trascendieron al conocimiento público sobre los argumentos evocados por Chile y Bolivia en los escritos previos, todo ello antes que el tribunal autorizara oficialmente su entrega a la publicidad, al iniciarse la fase de los alegatos orales. Ahora ya son ampliamente conocidos.

Lo hacemos por cuanto su sola lectura permite evidenciar que durante este debate preliminar fue imposible que las partes pudieran evitar entrar de lleno a evocar elementos más propios a una discusión sobre los aspectos de fondo del diferendo sin perjuicio de aquellos de carácter procesal. Esta constatación nos permite presumir que cuando se ingrese a la nueva etapa acerca de los méritos de esta causa, a contar del 25 de julio de 2016, fecha fijada para la presentación de la Contra Memoria chilena, no habrá muchas novedades en sus factores más substantivos. 


\section{Resumen de la posición planteada por Chile en su excepción preliminar}

Los planteamientos contenidos en la demanda boliviana dejan en evidencia que Bolivia persigue algo mucho más ambicioso que una obligación de negociar, como simplificadamente se ha venido sosteniendo en la prensa; lo que pretende Bolivia es que nuestro país sea obligado a negociar y finalmente conceder un acceso soberano al Océano Pacífico (obligación de resultado). La negociación reclamada por Bolivia es una que debe terminar en ese resultado concreto.

Bolivia confunde aspiraciones con derechos y que el Estado de Chile continuará actuando guiado por sólidas convicciones y valores jurídicos, que sustentan su política exterior. Ella se basa en el respeto irrestricto a los tratados de límites y en particular al Tratado de Paz y Amistad de 1904, que fijó definitivamente la frontera entre Chile y Bolivia, y que ha sido -y seguirá siendo- cumplido íntegramente por nuestro país. En este contexto, Chile considera fundadamente que la demanda boliviana pretende, en definitiva, que la Corte ordene una revisión de los términos acordados y de los limites pactados en el Tratado de Paz y Amistad de 1904. Para Chile es evidente que la demanda busca alterar lo pactado en 1904 y vulnerar el principio base del derecho internacional: el pacta sunt servanda. Asimismo, está en juego no sólo la observancia de los tratados vigentes sino también la estabilidad de las fronteras, principio que también tiene una especial protección en el derecho internacional.

Chile ha manifestado invariablemente que con Bolivia no existen conflictos territoriales ni marítimos, pues en su criterio estos problemas fueron resueltos precisamente por el referido Tratado de 1904. Chile argumenta asimismo que el petitorio de Bolivia, que solicita que la CIJ "falle y declare que Chile tiene la obligación de negociar con Bolivia con el objeto de alcanzar un acuerdo que otorgue a Bolivia un acceso plenamente soberano al océano Pacífico" tiene como resultado final modificar el Tratado de 1904, por lo tanto, y en mérito al artículo VI del Pacto de Bogotá, la Corte estaría inhibida de conocer la demanda boliviana.

Finalmente, la excepción chilena solicita la aplicación del artículo VI del Pacto de Bogotá. Dicha disposición excluye expresamente de la jurisdicción de la CIJ aquellas materias que han sido resueltas por acuerdo entre partes o que se hallan regidas por tratados anteriores a la fecha de celebración del mismo (30 de abril de 1948). Al respecto, Chile afirma que el Tratado de Paz y Amistad de 1904 resuelve y rige el asunto traído ante la Corte por Bolivia (el acceso soberano al mar), y por ende, queda fuera de la jurisdicción del Tribunal. 


\section{Síntesis de la posición de Bolivia planteada en sus escritos}

Bolivia sostiene que su pretensión (que se declare la obligación de negociar un acceso soberano) es un asunto diferente e independiente del Tratado de 1904, que no tiene ninguna relación con él y que su acción no tiene por objeto alterarlo.

Asimismo, argumenta que la excepción planteada por Chile está orientada a vincular, aún de manera forzada, la demanda de Bolivia con el Tratado de 1904, refutando dicho argumento y ratificando los términos de la demanda, en la cual no hace alusión alguna al Tratado de 1904. Chile lo haría así a fin de restarle jurisdicción y competencia a la Corte, por las previsiones señaladas en el artículo VI del Pacto de Bogotá. En consecuencia, Bolivia sostiene que su demanda, no implica directa ni indirectamente la modificación del Tratado de Paz y Amistad de 1904.

Agrega que Chile "está intentando hacerle creer a la comunidad internacional que Bolivia quiere modificar la arquitectura internacional de los tratados", lo cual no es cierto, porque Bolivia no está poniendo en cuestión el Tratado de 1904 y que "el eje de su demanda son los compromisos formales que Chile le hizo a Bolivia de entregarle soberanía”.

En este contexto, añade que su demanda, en tanto que busca un diálogo para una salida soberana al Pacífico, no está directa ni indirectamente relacionada con el Tratado de 1904, sino que con los compromisos unilaterales de Chile que habrían generado derechos jurídicos.

Con ese propósito, en el acápite relativo a los "Fundamentos jurídico" de su demanda, Bolivia destaca una serie de compromisos a través de los cuales "Chile se ha comprometido a negociar una salida soberana al mar para Bolivia a través de acuerdos, práctica diplomática y una serie de declaraciones atribuibles a sus representantes del más alto nivel"19. Entre esos compromisos, se mencionan el Convenio de Transferencia de Territorio de 1895; el Acta Protocolizada de 1920; el intercambio de notas de 1950; el Memorándum Trucco de 1961; y la declaración conjunta de Charaña de 1975, "entre otros numerosos instrumentos [que] evidencian que Chile se comprometió a encontrar una solución al enclaustramiento marítimo de Bolivia mediante negociaciones con miras a llegar a un acuerdo".

19 Ellos constituirían los actos jurídicos unilaterales que Bolivia eligió como elemento central de la postura legal de la demanda toda vez que, a su juicio, justificarían el valor probatorio de las llamadas "obligaciones no cumplidas por Chile". 


\section{Réplica chilena a estos argumentos}

Por "arte de magia", el Tratado de 1904 ha desaparecido de los fundamentos jurídicos que se mencionan en la demanda inicial y a este instrumento bilateral solo se le recuerda como "un antecedente histórico de la pérdida del litoral boliviano".

En resumen, Bolivia pretende "de una manera encubierta" desconocer el Tratado de Paz y Amistad de 1904.

Es imposible entender la demanda boliviana y que ésta resultara exitosa sin que afectara un tratado que fijó las fronteras entre Chile y Bolivia y que ha estado vigente por más de 100 años. Lo que Bolivia pide a la Corte es que obligue a Chile a negociar un acceso soberano al Océano Pacífico, es decir, le está pidiendo que obligue a Chile a alterar su integridad territorial. 